$\cdots$

NASA Contractor Report 191019

AIAA-93-0171

$$
\begin{aligned}
& 111-34 \\
& 137549
\end{aligned}
$$

p. 18

\title{
Advancements in the LEWICE Ice Accretion Model
}

William B. Wright

Sverdrup Technology, Inc.

Lewis Research Center Group

Brook Park, Ohio

January 1993

Prepared for

Lewis Research Center

Under Contract NAS3-25266

(NASA-CR-191019) ADVANCEMENTS IN

N93-15402

THE LEWICE ICE ACCRETION MODEL

Final Report (Sverdrup Technology)

$18 p$

Unc 1 is 


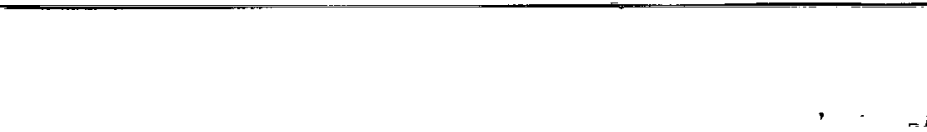




\title{
ADVANCEMENTS IN THE LEWICE
}

\author{
ICE ACCRETION MODEL
}

William B. Wright

Sverdrup Technology, Inc.

Brook Park, OH 44142

\begin{abstract}
12

ecent evidence has shown that the NASA/Lewis Ice Accretion Model, $L E W I C E$, does not predict accurate ice shapes for certain glaze ice conditions. This paper will present the methodology used to make a first attempt at improving the ice accretion prediction in these regimes. Importance is given to the correlations for heat transfer coefficient and ice density, as well as runback flow, selection of the transition point, flow field resolution, and droplet trajectory models. Further improvements and refinement of these modules will be performed once tests in NASA's Icing Research Tunnel, scheduled for 1993, are completed.
\end{abstract}

\section{NOMENCLATURE}

\begin{tabular}{|c|c|}
\hline A & Area $\left(m^{2}\right)$ \\
\hline$A_{3}$ & Area at surface of bead $\left(\mathrm{m}^{2}\right)$ \\
\hline$A_{4}$ & Area al top of bead $\left(\mathrm{m}^{2}\right)$ \\
\hline$b$ & Bead height (m) \\
\hline$b_{\mathrm{av}}$ & Rectangular bead height (m) \\
\hline $\mathrm{C}_{\mathrm{p}}$ & Heat capacity $(\mathrm{J} / \mathrm{kg} \cdot \mathrm{K})$ \\
\hline$e^{r}$ & Vapor pressure $\left(\mathrm{N} / \mathrm{m}^{2}\right)$ \\
\hline $\mathrm{F}$ & Wetness factor (dimensionless) \\
\hline $\mathbf{g}$ & Acceleration due to gravity $\left(\mathrm{m} / \mathrm{s}^{2}\right)$ \\
\hline h & Heat transfer coefficient $\left(\mathrm{W} / \mathrm{m}^{2-} \mathrm{K}\right)$ \\
\hline $\mathbf{k}$ & Thermal conductivity $\left(\mathrm{W} / \mathrm{m}^{\circ} \mathrm{K}\right)$ \\
\hline $\mathcal{L}$ & Lewis number (dimensionless) \\
\hline $\mathbf{L}_{\mathrm{f}}$ & Latent heat of fusion $(\mathrm{J} / \mathrm{kg})$ \\
\hline $\mathrm{L}$ & Latent heat of vaporization $(\mathrm{J} / \mathrm{kg})$ \\
\hline LWC & Liquid water content of air $\left(\mathrm{kg} / \mathrm{m}^{3}\right)$ \\
\hline m & Mass $(\mathrm{kg})$ \\
\hline MW & Molecular weight $(\mathrm{kg} / \mathrm{kg} \mathrm{mol})$ \\
\hline$N_{f}$ & Freezing fraction (dimensionless) \\
\hline$\overline{\mathbf{P}}$ & Static pressure $\left(\mathrm{N} / \mathrm{m}^{2}\right)$ \\
\hline $\mathbf{R}$ & Radius of sphere (m) \\
\hline $\mathrm{R}_{\mathbf{o}}$ & Radius of original drop $(\mathrm{m})$ \\
\hline$R_{w}$ & Mass flux of impinging water $\left(\mathrm{kg} / \mathrm{m}^{2} \mathrm{~s}\right)$ \\
\hline
\end{tabular}

Released to AIAA to publish in all forms.

This paper is declared a work of the U.S. Government and is nol subjerl to copyright protection in the Unlted States. 


\section{Greek Letters:}

B Collection efficiency (dimensionless)

$\mu_{\mathrm{f}} \quad$ Viscosity $(\mathrm{kg} / \mathrm{m}-\mathrm{s})$

$v \quad$ Thermal diffusivity $\left(\mathrm{m}^{2} / \mathrm{s}\right)$

$v_{\mathrm{f}} \quad$ Kinematic viscosity $\left(\mathrm{m}^{2} / \mathrm{s}\right)$

$\theta \quad$ Contact angle (radians)

$\rho$ Density $\left(\mathrm{kg} / \mathrm{m}^{3}\right)$

$\sigma \quad$ Surface tension $(\mathrm{N} / \mathrm{m})$

$\tau \quad$ Time scale (sec)

$\tau_{f} \quad$ Shear stress $\left(\mathrm{N} / \mathrm{m}^{2}\right)$

\section{Subscripts:}

\begin{tabular}{|c|c|}
\hline a & air \\
\hline c & convection \\
\hline cond & conduction \\
\hline & edge of boundary laye \\
\hline evap & evaporation \\
\hline $\mathrm{f}$ & fluid \\
\hline ke & kinetic cnergy \\
\hline & liquid \\
\hline & total property \\
\hline ec & recovery propenty \\
\hline & solid \\
\hline $\operatorname{sens}$ & sensible heat Iransfer \\
\hline & water \\
\hline & free-stream property \\
\hline
\end{tabular}

\section{Abbreviations:}

$\begin{array}{ll}\text { LEWICE/P } & \begin{array}{l}\text { Original Two-Dimensional Potential } \\ \text { Flow Ice Accretion Program }\end{array} \\ \text { LEWICE/BL } & \text { lce Accretion Program Using Potential } \\ & \text { Flow with Interactive Boundary Layer } \\ \text { LEWICE/E } & \text { Euler Flow Ice Accretion Program }\end{array}$

LEWICE/NS Navićr-Stokes Flow Ice Accretion Program

LEWICE $T$ LEWICE/P Program with Conduction and Electrothermal Deicer Modelling Capability

LEWICE/TNG LEWICE/P Program with Improved Ice Physics Model

\section{INTRODUCTION}

12 ecently, several advancements have been made in the development of ice accretion theory. It is the purpose of this report to incorporate these advancements into the NASA/LEWIS ice accretion program LEWICE'. Specifically, attention is focused in (wo areas. First, a methodology is formulated for predicting the 'sand-grain' roughness model which controls transition and the level of convective heat Iransfer. Second, a new formulation is developed for modelling runback water flow. The previous methodology, originally formulated by Messinger ${ }^{2}$, results in a constant flow of runback water at the surface for glaze ice conditions. However, based on the evidence presented by Olsen ${ }^{3}$ and more recently by Hansman ${ }^{4}$, it has been shown that there is a short transient at work in the ice accretion process, and that past this initial phase, much less surface water flow occurs. This paper will present a new runback model in an altempt at modelling this initial transient.

The first section of this paper will be to present enhancements in the $L E W I C E$ model based on previous experimental data and theoretical advancements developed by other researchers. It was found that although several researchers had made specific improvements to the program, or had performed tests for the purpose of improving this program, a single code which combined all of these previous achievements did not exist. Specifically, improvements made by Cebecis in fluid flow, Rios ${ }^{6}$ in ice density, Poinsatte ${ }^{7}$ in heat transfer, Hansman ${ }^{4}$ and Yamaguch ${ }^{8}$ in transition modelling, Al-Khali ${ }^{9}$ in runback flow and Wright ${ }^{10}$ in heat conduction were incorporated into this program.

The second section of this paper will be to develop equations which model the transient freezing of a single drop of water on the airfoil surface. The equations for the geometry of a drop will also be developed. Also, the flow rate of a liquid film will be determined using this analysis, following the methodology developed by Al-Khalil ${ }^{9}$. As droplets freeze, they will form a roughened surface much 
more rough than the original airfoil surface and much rougher than typical 'sand-grain' roughness. It is the purpose of this section to make a first attempt at predicting a characteristic roughness height based on a limiting case analysis of surface tension controlled water flow.

\section{IMPROVEMENTS TO THE MODEL}

\section{Flow Field Resolution}

The potential flow solution for iced geometries can be very irregular, resulting in several calculated stagnation points. Since the integral boundary layer technique used in LEWICE needs a single stagnation point to start at, the calculated iced geometry is smoothed so that only one stagnation point is calculated. The technique used in the current version was developed by Cebeci ${ }^{5}$. He calculales a smoothed 'pseudo-surface' which is used only in the calculation of the flow field. In the current model, the flow solution was smoothed instead of the airfoil coordinates.

The potential flow code is preferred for the development of a new ice accretion theory over more complex, Euler, or Navier-Stokes codes available due to the faster execution time. As this ice accretion module become further developed, an analysis will be performed to determine the necessary complexity of the flow solution.

\section{Droplet Trajectories}

The enhancements made to the droplet trajectory algorithm are primarily concerned with the speed of the calculation. Since approximately $80 \%$ of the computational time in LEWICE is spent calculating droplet trajectories, methods of speeding up this module were investigated.

Three improvements were made in this area. First, the initial point for calculation was started at a y-localion determined by the angle of allack of the flow, not parallel to the airfoil. This results in fewer trajectories needed to find the desired range. Even at an angle of attack of $4^{\circ}$, the program needs to compute only three trajectories to find the desired range. whereas previously it required six.

Second, during the determination of the impingement limits, the next starting point for a new trajectory was determined using a "weighting' factor. Previously, the next starting point for a new trajectory was hallway between a missed trajectory and a trajeclory which hit the surface. Currently, the next trajectory is started between these two limits, however, its starting location is 'weighted' such that the resuling Irajectory will tran el closer to the lop (or bollom) of the airfoil. This results in fever irajectories needed to find the impingement limits. This technique has not been as successful at decreasing the number of Irajectories. Usually only one or two trajectorics out of Iwelve are saved using this tochnique.

Finally, methods were investigated to reduce the number of air velocities needed. During each time step of each trajectory, the algorithm performs a prediclor-corrector iteration to solve the integration of the non-linear momentum equation. For this integration, the program requires the air velocity at that location. Previously, this has been found by summing the contribution from each panel in the potential flow solution. So far, two methods have been attempted to simplify this cumbersome computation.

First, the air velocity was simply lagged one time step. Thus for each iteration in the predictor-corrector, the same value of the air velocity was used. This assumption is valid, as the difference in position between predictor and corrector is much smaller than the distance between the drop position at time step $n$ and its position at lime step $n+1$. This modification in itself can decrease the computation time by a factor of three and thus merits further investigation in three-dimensional codes as well as more complex two-dimensional codes.

Second, instead of calculating the air velocity for each step in the trajectory routine, velocities were calculated on an off-body rectangular grid and an interpolation scheme was used to find values in belween grid points. This results in fewer air velocities which need to be calculated. This method also reduced the computation time, although the improvement is not as great if a fine mesh is used. This happens because the number of panels is small in a twodimensional code. Further invesligalion is waranted in three dimensional codes for this method.

Finally. one correclion was made to the droplet trajectory algorithm to increase its accuracy. This correction is concemed with the 'd-shift" used in LEWICE. When calculating the off-body air velocity at any location using a potential flow solution. the answer will not be reliable if the point lies too close to any given panel. To alleviate this problem. LEWICE creales a set of coordinates which lic a distance 'd-shift" nommal from the surface.

Previously. when a drop hits the enlarged surface, it was treatled as if it hit the actual surface. This results in an over prediction of the colleclion efficiency because drops which might impinge the barger 'd-shifted' surface might not hit the actual surfice. Cumently. the drops are allowed to proceed until they impinge the actual surface. However. 
if the distance between the drop and a given panel is less than ' $d$-shift', the air velocity which is used will be interpolated from the value at a location ' $d$-shift' from the panel and the value at the panel which is provided from the potential flow solution. This is illustrated in Figure 1.

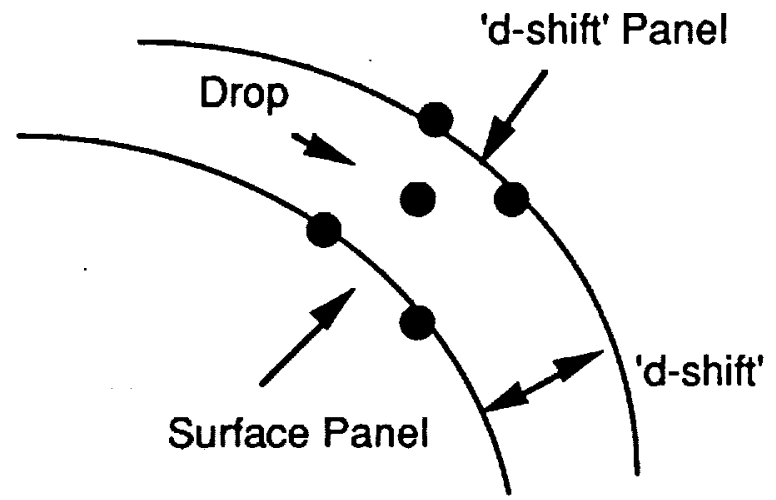

Figure 1. Location of Drop Within 'D-Shift' of Surface

\section{Heat Transfer Coefficient}

The heat transfer coefficient in $L E W I C E$ is controlled via the skin-friction which in turn is controlled by the equivalent sand-grain roughness. In glaze ice conditions, when all of the ice does not freeze upon impact, the local freezing rate can be greatly controlled by the heat transfer coefficient. The current model still relys on the sand-grain roughness; however, the correlation itself has been corrected to more closely reflect heat transfer coefficient data taken by Poinsatte' using the NASA/Lewis Twin Otter Research Aircraft and using the Icing Research Tunnel.

In that study, hemispherical elements were glued onto a NACA0012 airfoil with heater elements in the airfoil. The heaters were kept at a constant temperature of $60^{\circ} \mathrm{F}$ and the necessary heat supplied was recorded for various Reynolds numbers and angles of attack. Four different roughness pattems, including a clean airfoil, were used in this study.

These tests are not considered ideal for use in LEWICE, as it does not use actual ice roughness. However, they provide a means of modifying the correlation for large sand grain roughnesses. Since the element heights were $1 \mathrm{~mm}$, a sand grain roughness of $1 \mathrm{~mm}$ was used for comparison with the $L E W I C E$ correlation. $L E W I C E$ greatly overpredicted the heat transfer coefficient using this value. Three corrections were made which resulted in better agreement with the experimental results.
First, the temperature dependance of both the thermal conductivity and viscosity were corrected. Based on what appears to be a typographical mistake in the coding, the temperature dependance of these variables was too high.

Second, the computation of the transition Reynolds number was changed when the roughness height exceeds the boundary layer thickness. Transition will still occur when the Reynolds number based on roughness exceeds 600 . However, if the roughness height exceeds the boundary layer thickness, the definition of the Reynolds number is changed. Previously, the velocity was set to the velocity at distance $\delta$, i.e., the potential flow solution. The roughness height was still used in the calculation. Currently, the routine uses the boundary layer thickness instead of the roughness height in the Reynolds number calculation.

$$
\begin{aligned}
& \text { Previous Definition: } R e_{k}=\frac{V_{\delta} k_{s}}{v} \text { for } k_{s}>\delta \\
& \text { Current Definition: } R e_{k}=\frac{V_{\delta} \delta}{v} \text { for } k_{s}>\delta
\end{aligned}
$$

Third, the turbulent roughness value was calculated by the roughness height model described later in this paper. Any roughness in excess of the turbulent boundary layer thickness is treated as follows:

1) The roughness height up to the boundary layer thickness directly affects the convective heat transfer as a sand-grain roughness.

2) The amount beyond this level affects the convective heat transfer only due to the flow acceleration over this protuberance which can be calculated by the flow solver.

Using these corrections, much better agreement was achieved with Poinsatte's experimental data. Future tests are planned which will attempt to measure heat transfer coefficient on plastic ice models.

\section{Ice Density}

The ice density correlation used in $L E W I C E$ was developed by Macklin ${ }^{11}$ using tests on rotating cylinders. The Macklin correlation is based on three parameters: the local surface temperature, the volume median droplet diameter, and the droplet impact velocity. This correlation is believed to be inaccurate because it is based on a parameter which was not measured in the test (droplet impact velocity). Macklin calculated the impact velocity from measured variables using a very simplified analysis. 
Rios" presented an alternative ice densily correlation hased on tests performed by Jones': These iests were also performed on rotating cylinders and hence are not ideal for ice prediction on airfoils. Il is hased on five paramelers: air temperature, air velocity, liquid water content, volumetric mean droplet diameter, and cylinder diameter. This relationship can, at best. only provide the average ice density as it is based on ambient parameters.

The implementation in $L E W I C E$ assumes that the functional form of the correlation can be applied at each chord location using the local equivalent to the ambient variable. The surface temperature, collection efficiency, and local radius of curvature are substituted into the correlation. This results in a chordwise variation of ice density for most conditions, with the higher glaze ice density at the leading edge, progressing to lower rime values downstream. The form of this correlation is given below.

$$
\ln \left(\rho_{i c e}\right)=-0.15 \times\left(1+60435^{-2.65}\right)
$$

where

$$
S=\frac{d_{m v d}^{0.82} \times V_{o}^{0.59} \times(\beta L W C)^{0.21}}{D_{l o c}^{0.48} \times\left(-T_{a i r}\right)^{0.23}}
$$

Future tests are planned which will measure the local density on airfoil ice shapes to verify this correlation.

\section{Runback Water Flow}

The methodology used in $L E W I C E$ assumes that water which impinges and does not freeze will automatically flow into the next control volume. This can result in relatively large water flow rates on the surface for glaze ice conditions. These large flow rates however are not supported by qualitative assessment of ice accretion tests or by close up videos.

The current model uses a formulation derived by AlKhalil' for runback water flow. In his model, water flow is assumed to be shear driven by the air flow. His formulation solved for the complex. Iwo-dimensional flow of surface water, typically using engine inlels equipped with an anti-icer. Since $L E W I C E$ is a two-dimensional flow program the airfoil surface is one-dimensional, hence the theory developed by Al-Khalil9 can be simplified in this paper.

This model has teen further modified by assuming that the 'weiness factor' described by Al-Khalil can be independently determined by the amount a drop spreads upon impact. This is determined from experimental data by Macklin's and hy Hansman' who measured the contact angle of the drop from which the spread factor can be determined. Additional tests are needed to confirm the relationship between contact angle and the ambient paramcters.

Additionally, the water is allowed to stagnate if the force of the flow is found to be less than the surface tension force. This model has the advantage of modelling slanding water in each control volume, and should be accurate for modelling separation regions in NaviérStokes flow, since water will not flow into a separation region.

\section{Heat Conduction}

Wright 10 modelled the two-dimensional transient conduction in an airfoil with ice accretion for the application of modelling an electrothermal deicer. When all internal heat sources are lurned off, this program will predict the ice accretion on an airfoil with conduction effects. However, this simplified application can be handled without the additional computational burden. An analytic solution is available which gives a reasonable approximation for this case. Locally, at each chordwise location, the heat conduction can be modelled using a semi-infinite flat plate assumption where the airfoil surface at time $=0$ is suddenly raised from the recovery temperature to the icing temperature (normally $0^{\circ} \mathrm{C}$ in glaze ice conditions). This assumption has been verified by performing parameter runs using the full conduction model. Since the airfoil skin thickness is not infinite, this assumption can remain in effect only until the heat has penetrated through the airfoil skin. The parameter used to measure this is termed the penetration thickness. When the penetration thickness equals the airfoil thickness, the heat has penetrated through the airfoil skin. At this point in time, the conductive flux at the surface is small enough to be ignored.

\section{Liquid Water Content}

The physical evidence obtained from tests performed so far show that the final ice shape is greatly dependant upon the physics during the first few seconds. It is felt that a large amount of the repeatability problems in generating experimental ice shapes stems from an inability to exactly match, either in flight or in the IRT, the exact variation in conditions. This is especially true during this initial lime frame. It has been established in the IRT that liquid water 
content will increase from 0 to the desired LWC value within about $20 \mathrm{sec}$. The program currently is capable of modelling this transient linearly. At present, no parametric studies have been performed to determine the effect of different LWC transients on the final ice shape, nor have any flight cases been evaluated for this purpose.

\section{GLAZE ICE ACCRETION MODEL}

As stated earlier, the experimental evidence as shown by Olsen ${ }^{3}$ and Hansman ${ }^{4}$ clearly show that the current methodology for ice accretion is incorrect when applied to glaze ice. However, much of this data is qualitative in nalure. which makes it difficult to incorporate into a computer model. The following analysis presents a first step at modelling some of these phenomena. Where quantitative data exists, this model will be compared to these experiments.

\section{Bead Geometry}

Assume that as a spherical droplet of water impinges a locally flat surface and deforms, it retains a spherical form with a section cut from the bottom (see Figure 2).

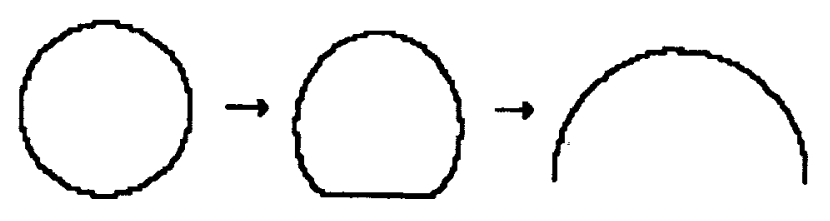

Figure 2. Dispersement of Water Droplet

Furthermore, assume that in the short time it takes this drop to stabilize that the volume remains constant. This assumes that evaporation losses are small and that little of the ice has frozen. As it is assumed the drop takes on the order of $10^{-7}$ sec. to stabilize at any given contact angle, these assumptions are reasonable. This time scale is derived by dividing the drop diameter by the drop velocity. This volume at any given angle can be determined as the volume of a sphere with a conical section cut from it plus the volume of a fiat-bottomed cone with an equal angle. This is represented in Figure 3.

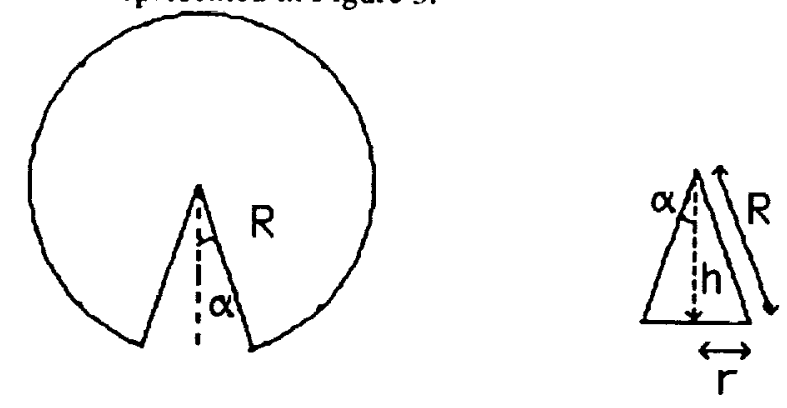

Figure 3. Representation of Partial Volume of Sphere

This volume can be represented mathematically by adding the volume of a sphere with a conical section cut out plus the volume of a flat-bottomed circular cross-section cone. The first of these volumes is found by integrating

$$
V=\int_{0}^{R} \iint_{0}^{\pi} \pi r^{2} \sin \theta \sin \phi d \phi d \theta d r
$$

If this equation were integrated from 0 to $\pi$ instead of $\alpha$ to $\pi$, the equation for the volume of a sphere is obtained.

The volume of a cone is given by

$$
V=\frac{\pi}{3} r^{2} h
$$

or by writing this in terms of the sphere diameter $R$ (the hypotenuse of the triangle with sides $h$ and $r$ ),

$$
V=\frac{\pi}{3} R^{3}\left(\cos \alpha-(\cos \alpha)^{3}\right)
$$

The total volume of this section is then

$$
V=\frac{\pi}{3} R^{3}\left(2+3 \cos \alpha-(\cos \alpha)^{3}\right)
$$

where again $R$ is the radius of the sphere, and $\alpha$ is the angle at which the sphere is cut off (see Figure 3 above).

For $\alpha>\pi / 2$, the segment of the sphere which contains the mass of the drop is less than half of the total volume of that sphere. The volume can be represented by subtracting the above volume from the total volume. This yields

$$
V=\frac{\pi}{3} R^{3}\left(2-3 \cos \theta+(\cos \theta)^{3}\right)
$$


However, this equation gives the volume in lerms of an angle which is equal to $\pi-\alpha$. To be consistent, the angle can then be changed back to the same point as the above volume (see Figure 4).

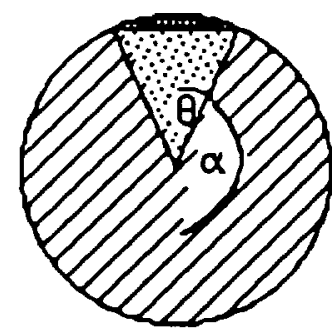

Figure 4. Sphere Divided into Separate Regions

Performing this substitution yields

$$
V=\frac{\pi}{3} R^{3}\left(2+3 \cos \alpha-(\cos \alpha)^{3}\right)
$$

which is the same equation obtained before for $\alpha<\pi / 2$, hence the above equation describes the deforming sphere at any angle. It is assumed that as more drops impinge or as drops coalesce that only the mass is changed and that the geometry remains the same.

\section{Energy Equation}

The energy equation for a given drop at known contact angle is found by making the following assumptions:

- 1) No part of the drop goes below freezing until the entire drop is frozen. hence $T_{\text {wer }}=T_{\text {mell: }}$;

- 2) Conduction heat loss and sensible heat uransfer occurs only at the interface between the surface and the drop:

- 3) Evaporation and convection occurs at the water/air interface:

- 4) Ice forms at the bollom surface of the drop: and.

- 5) The themal properties of the solid surface can be found by adding the thermal resistances of each layer (including the ice) in a composite siructure.

Following the derivation of Wright' ${ }^{10}$, the energy balance on an individual drop is given by

$$
\begin{gathered}
-k\left(\frac{d T}{d y}\right)_{y=0}+h_{c}\left(T_{r e c}-T_{m}\right)+\frac{1}{2} R_{w} V_{\infty}^{2} \\
+R_{w} C_{p_{l}}\left(T_{-}-T_{m}\right)+\frac{L_{v} M_{w} h_{c}}{P_{u} C_{p_{c}}}\left(e_{e}-e_{s} \frac{T_{e}}{T_{s}}\right) \\
=R_{w} L_{f} N_{f}
\end{gathered}
$$

$T_{\text {rec }}$ represents the recovery temperature, as defined by Schlichting ${ }^{14}$.

However, this analysis does not account for the difference in area between the icing surface (which is presumed flat) and the surface area of the bead. Furthermore, it is more convenient for the current analysis to replace the accretion rate $R_{w} N_{f}$ as $\rho_{\mathbf{z}} \mathrm{db} / \mathrm{d}$, where instead of using the freezing fraction, the increasing thickness of the ice $\mathrm{db} / \mathrm{dt}$ is used instead. If $A_{t} / A_{1}$ represents the ratio of the top surface area to the flat surface area, the energy equation becomes

$$
\begin{gathered}
-k\left(\frac{d T}{d y}\right)_{y=0}+h_{c}\left(T_{r e c}-T_{m}\right) \frac{A_{l}}{A_{s}}+\frac{1}{2} R_{w} V_{\infty}^{2} \\
+R_{w} C_{p_{t}}\left(T_{-}-T_{m}\right)+\frac{L_{v} M_{w} h_{c} A_{f}}{P_{a} C_{p_{a}} A_{s}}\left(e_{e}-e_{s} \frac{T_{e}}{T_{s}}\right) \\
=\rho_{s} L \frac{d b}{f d t}
\end{gathered}
$$

Since the drop is very small compared to the thickness of the surface, and since the drop temperature can be assumed to be close to $T_{\text {mett }}$ until it freezes completely, the heat loss into the surface can be expressed as the analytic solution of heating a semi-infinite slab, hence

$$
-\left.k \frac{d T}{d y}\right|_{y=0}=\frac{k\left(T_{\text {rec }}-T_{m}\right)}{\sqrt{\pi v \tau}}
$$

where $v$ is used as the thermal diffusivity in order to avoid confusion with the angle $\alpha$. To simplify future equations, the energy equation is rewritten in terms of a temperature difference times an effective $h$ for that term. This yields 


$$
\begin{gathered}
h_{\text {cond }}\left(\Delta T_{\text {rec }}\right)\left(\frac{\tau}{t}\right)^{0.5}+h_{c}\left(\Delta T_{\text {rec }}+\Delta T_{\text {evap }}\right) \frac{A_{1}}{A_{s}} \\
+h_{\text {sens }}\left(\Delta T_{\text {rec }}+\Delta T_{\text {ev }}\right)=\rho_{s} L_{f} \frac{d b}{d t}
\end{gathered}
$$

where

$$
\begin{gathered}
h_{\text {cond }}=\frac{k}{\sqrt{\pi v \tau}} \\
h_{\text {sens }}=R_{w} C_{p_{l}} \\
\Delta T_{k e}=\frac{V_{\infty}^{2}}{2 C_{p_{l}}}+T_{\text {rec }}-T_{\infty} \\
\Delta T_{\text {rec }}=T_{m}-T_{\text {rec }} \\
\Delta T_{\text {evap }}=\frac{L_{v} M_{w}}{P_{a} M_{a} C_{p_{c}} \mathcal{L}^{\frac{2}{3}}}\left(e_{e}-e_{m} \frac{T_{e}}{T_{m}}\right)
\end{gathered}
$$

and where $\tau=$ representative time scale.

The maximum value of the rate of freezing will occur when the rate of freezing above exceeds the rate of impingement, which is

$$
\frac{d b}{d t}=\frac{R_{w}}{\rho_{s}}
$$

The amount of water on the surface at any time can be found by subtracting the rate of ice formation from the rate of impingement and integrating. Note that since the quantity $R_{w}$ is defined in terms of the liquid water content, this value is not necessarily constant.

The following geometric parameters can now be defined as follows. Let $b_{\mathrm{w}}$ be defined the average height of the bead, $s$ is the diameter of the spread bead, and $b$ is the bead height, as shown in Figure 5.

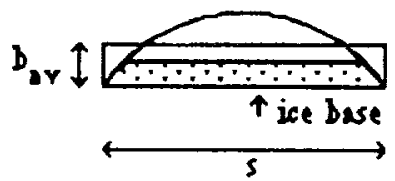

Figure 5. Geometry of Water//ce Bead

From simple trigonometry relations.

$$
\begin{gathered}
s=2 R \sin \theta \\
b=R(1-\cos \theta)
\end{gathered}
$$

where $\theta$ is the contact angle. which is defined as the tangent angle of the drop where it intersects the surface. Note that $\theta=\pi-\alpha$. The volume of the bead can be expressed as the volume of a cylinder with diameter $s$ and height $b_{\text {av }}$ or as the partial volume of a sphere as before. Equaling these two yields

$$
\frac{\pi}{4} s^{2} b_{a v}=\pi R^{3}\left(2-\cos \theta+(\cos \theta)^{3}\right)
$$

Substituting the relations for $b$ and $s$ into this expression yields

$$
b_{a v}=b \frac{(2+\cos \theta)}{(1+\cos \theta)}
$$

The area ratio is the ratio of the exposed surface area to the area at the base.

$$
\begin{gathered}
\frac{A_{t}}{A_{s}}=\frac{2 \pi R^{2}(1-\cos \theta)}{\pi R^{2}(1-\cos \theta)(1+\cos \theta)} \\
=\frac{2}{(1+\cos \theta)}
\end{gathered}
$$

hence the total ice accretion rate becomes

$$
\begin{gathered}
h_{c}\left(\Delta T_{r e c}+\Delta T_{\text {evap }}\right) \frac{2}{(1+\cos \theta)} \\
+h_{\text {cond }}\left(\Delta T_{\text {rec }}\right)\left(\frac{\tau}{t}\right)^{0.5}+h_{\text {sens }}\left(\Delta T_{\text {rec }}+\Delta T_{\text {, }}\right) \\
=\rho_{s} L_{\delta l}^{d b}
\end{gathered}
$$

\section{Water Flow Criteria}

At a certain point, if enough water forms on the surface, it will form a continuous film and start to flow. This will happen when the shear force on the water overcomes the surface iension forces. From Al-Khalit".

$$
\frac{d m_{f}}{d l}=\frac{F \tau_{f}}{2 v_{f}} b^{2}
$$


where $m_{f}$ is the mass per unit span, $\tau_{f}$ is the shear stress, $v$ is the kinematic viscosity, and $F$ is the wetness factor, the fraction of the surface covered with water. The velocity of the water flow is given by

$$
v_{f}=\frac{F \tau_{f}}{2 \mu_{f}} b
$$

The force per unit span is obtained by multiplying the velocity by the mass flow rate to get

$$
F_{\text {flow }}=v_{f d t}^{d m}=\rho_{l}\left(\frac{F \tau_{f}}{2 \mu_{f}}\right)^{2} b^{3}
$$

This quantity has the same units as surface tension, $\sigma$. When this quantity is greater than the surface tension, the bead will flow. Performing this operation yields the flow criteria for water runback

$$
b>\left(\frac{4 \sigma \mu^{2}}{\rho_{l} F^{2} \tau^{2}}\right)^{\frac{1}{3}}
$$

where $\sigma=$ surface tension.

Additionally, the flow can be affected by gravitational forces. The method in which gravity is modeled is to assume that there is a limiting drop height above which the drop becomes unstable at that contact angle and starts to flow. If the drops are small, they retain their shape, but if more water is added, the drop will reach a mass beyond which flow will occur. This will happen when

$$
m g b \cos \psi>\sigma A
$$

where $\psi$ is the local angle the airfoil makes with a horizontal line. By substituting the proper geometric equivalents,

$$
b>\sqrt{\frac{\pi \sigma(1-\cos \theta)}{\rho g \cos \psi}}
$$

One of the unknown parameters in the above development is the wetness factor, $F$ (see equation 30 ). The following strategy will be adopted here for calculating this variable. There is a quantity called the 'spread factor', which was defined by Macklin ${ }^{13}$ as the ratio of the diameter of the spread drop to the initial drop diameter, and is determined by equating the expresston for the volume of a spread drop with the original spherical volume,

$$
\frac{\pi}{3} R^{3}(2+\cos \theta)(1-\cos \theta)^{2}=\frac{4}{3} \pi R_{0}^{3}
$$

Substituting the previous expression for the spread drop diameter $s$ into this equation yields

$$
S=\frac{s}{2 R_{0}}=\left[\frac{4 \sin \theta(1-\cos \theta)}{(2+\cos \theta)(1-\cos \theta)}\right]^{\frac{1}{3}}
$$

According to Macklin ${ }^{13}$, a surface is considered completely welled when the contact angle is below $10^{\circ}$. The wetness factor can then be defined as the ratio of the spread factor at the contact angle $\theta$ to the spread factor at an angle of $10^{\circ}$, with an upper limit of $F=1$.

As a check on the previous equation, both Macklin'3 and Hansman ${ }^{4}$ performed experiments to determine the variation of drop geometry with temperature. Hansman measured the contact angle from close-up movies while Macklin measured the diameter of individual frozen drops with a micrometer, then divided by the known diameter of the incoming drops to obtain the 'spread factor'. A comparison of the data by these two researchers is presented below.

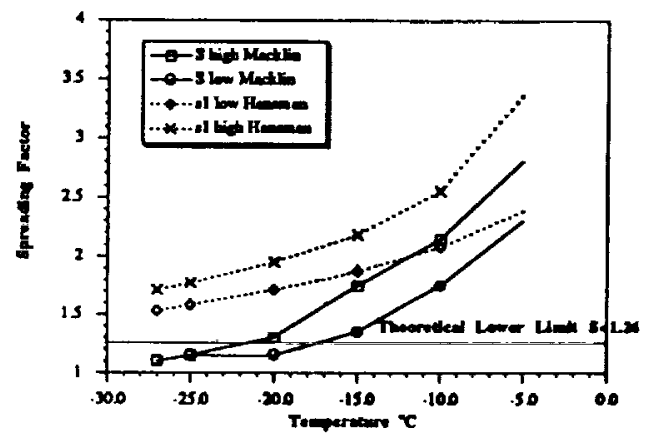

Figure 6. Comparison of Experimental 'Spread Faclor'

The upper line in the above plot gives the largest spread factor for that temperature while the lower line gives the smallest value for that temperature. The difference between the upper and lower values represents the scatter in the data. The theorelical lower limil show'n in this plot is computed by inputting the value for a hemispherical bead which is $\theta=\pi / 2$. The agreement between the two tests show the same trends. however both parame- 
ters are difficult to measure accurately. as shown by the data scatter.

\section{Computational Strategy}

The bead height model used in this paper only identifies the maximum possible roughness level that can be obtained. These maximum values are based on physical criteria. The actual roughness of the surface is unknown. as it could be less than these values. For this analysis, the roughness heights used was the smallest of these maximums. These criteria are as follows:

1) Roughness height can not exceed the ice thickness:

2) Water height can not exceed the height needed to flow based on the shear forces exceeding the surface tension forces;

3) Water height can not exceed the height needed to flow based on the gravitational forces exceeding the surface tension forces:

4) For both 2) and 3) the total bead height is determined using the water height and the freezing fraction;

5) Heat transfer coefficients are affected by bead height only up to the boundary layer thickness, whether this is for transition or for turbulent values. The additional effect of heat transfer due to these beads is presumed to be handled by increased velocity in the flow solution.

The computational strategy for glaze ice accretion is as follows:

1) using a small time step ${ }^{1}$, water is allowed to impinge upon the airfoil;

2) the amount frozen, the liquid bead height and runback water flow (if any) are determined from the above equations:

3) the roughness height is set equal to the bead height;

4) boundary layer quantities are recomputed to determine new values for heat transfer coefficient;

5) time is incremented;

6) if the flow is undisturbed ${ }^{2}$ by the ice shape, return to step 1):

7) if the flow is changed, compute new flow field

I. The size of this step needed to ensure accuracy has not yet been established

2. The criteria for this has not been established. and trajectories, then return to step 1);

8) if the total simulation time has been reached, stop the simulation.

\section{RESULTS AND DISCUSSION}

The model presented in this paper has an implied assumption that the ice accretion process as a whole will be modeled better when each of the sub-models presented is accurate. Therefore, the first step in verifying this model will be to verify, if possible, the sub-model. However, for many of these sub-models, this can not be done as yet. Therefore, only qualitative assessments can be made as to their improvement. Except where otherwise noted, the cases used to present the capabilities of the model are taken from experimental runs by Shin ${ }^{15}$. Most plots were obtained using the following conditions: $\mathrm{V}_{\infty}=230 \mathrm{mph}$; $\mathrm{T}_{\mathrm{o}}=28^{\circ} \mathrm{F} ; \mathrm{LWC}=0.55 \mathrm{~g} / \mathrm{m}^{3} ; \mathrm{MVD}=20 \mu \mathrm{m} ; \mathrm{t}=7 \mathrm{~min} ; \alpha$ $=4^{*}$

\section{Flow Field Resolution}

Figure 7 shows a comparison of the output from the potential flow solver with the smoothed values after six minutes of ice accretion. Even though this solution is more uniform, it does not serve its full purpose of determining the stagnation point for the boundary layer routine. The stagnation point is determined by picking the point or points where the velocity changes sign, which still happens more than once. At this point, the program selects the new stagnation point as the one which is closest to the old stagnation point.

\section{Droplet Trajectories}

There were several modifications made to the droplet trajectory routine. Figure 8 shows the optimization of the range routine. For this particular case, placing the first $x, y$ - point at an angle $\alpha$ below the airfoil results in three fewer trajectories.

Figure 9 shows the effect of using a grid-based scheme to interpolate velocities. As can be seen in this plot, there is an insignificant difference in the path of the trajectory using this routine. However, the computational savings in $2 \mathrm{D}$ were also minimal. The use of this approximation will be more beneficial for $3 \mathrm{D}$ algorithms.

Figure 10 illustrates the approximation made when off-body air velocities are calculated only at the start of the 
lime step. This plot shows the $x, y$ location of the drop at lime $n$ and at lime $n+l$ every time the velocily rouline is called. Although it does not show well on this plot, the velocity routine is called six times at lime $n$ and eight times at time $n+1$. Currently, it is called once for each location. Again, there is no change in the trajectory of the drop. As the locations are so close, their individual locations can not be seen on the plot.

Figure 11 shows the effect on collection efficiency using the interpolation procedure within 'd-shift' of the surface. These results also incorporate the approximations described above. As can be seen from this plot, the effect of using different 'd-shifts' has been greally minimized. Figure 12 shows the difference in the 7 minute ice shape and the experimental comparison. Again, very minimal difference in ice shape prediction is seen. By contrast, Figure 13 shows the variation in predicled ice shape using the same two 'd-shifts'.

Figure 14 shows the variation in collection efficiency with time. Qualitatively, this result appears correct. The horns collect more water than the same location on the clean airfoil, while fewer drops collect at the stagnation point. However, no experimental validation of the quantitative values have been made, except for a clean airfoil. This could be a large source of the error in the predicted results.

\section{Heat Transfer Coefficient}

Figure 15 shows a sample comparison of both the current correlation and the previous correlation with the experimental data. As can be seen in this plot, much better agreement is achieved using the corrections described earlier. Since this experiment had only metal roughness elements and not ice. the bead height is known. This height is used unless it exceeds the boundary layer in either the laminar or turbulent regimes. This has the effect of moving transition downstream. Assuming that roughness levels exceeding the turbulent boundary layer can not be measured by the current correlation produced heat transfer levels approaching that of the experimental data.

\section{Heat Conduction}

Figure 16 shows a comparison belu'cen the approximate equation used for heat losses by conduction and the compulational heal losses by conduction using LEW/CE $T$. Good agreement is shown. validating that this approximation is reasonably accuratc for including conduction effects in ice accretion. The variation in the computational results are due to the fact that the heat conduction program is set up to analyze electrothermal heaters which will produce heat huxes two orders of magnitude greater than these levels. Hence the truncalion of the tinite-difference scheme comes into play for these very low heat flux levels.

\section{Bead Height Model}

Figure 17 shows the predicted maximum bead heights which are used as roughness heights in the program for two different time steps. The initial values vary gradually between $0.1 \mathrm{~mm}$ and $0.8 \mathrm{~mm}$. while al $t=360 \mathrm{sec}$. the variation is much more irregular. This is due to the irregularily in the potential flow solution. The flow field now has control over not only the bead height, but the runback flow as well. This advancement will hopefully allow better flow solvers, such as Naviér-Stokes to improve their ice accretion prediction much more so than a potential flow solver because the potential flow solver is not accurately predicting the flow behavior for glaze ice shapes.

\section{Ice Density}

Figure 18 shows an example of the chordwise density which can be achieved using the current correlation. This case was run using a total temperature of $-15^{\circ} \mathrm{F}$ instead of the $28^{\circ} \mathrm{F}$ temperature used for the other cases. This change was performed because ice density did not vary for the very warm glaze condition ran earlier. This is supported by both Macklin's and Jones's data which give an average ice density approaching the glaze ice value as temperature increases. Even though this is a pure rime case, much of the ice which forms has a density within $10 \%$ of the glaze valuc. This is why rime ice shapes have in the past compared well with experiments even though the ice shape formed in the experiment may have had a lower density.

\section{Ice Accretion Comparison}

Figure 19 shows a comparison between the predicted ice shape and the experimental ice shape presented by $S_{\text {Shin }}{ }^{15}$. He compared experimental ice shapes with those predicted by LEWICE/IBL. Most of these predictions are very good. The particular case chosen for comparison here was selected because the ice shape predicted by Shin $^{15}$ using $L E W I C E / I B L$ did not match the experimental data. 
The program created for this paper has been called LEWICE/TNG (LEWICE: The Next Generation) for comparison with previous models. Currently, the overall ice prediction with $L E W I C E / T N G$ is not very much improved over $L E W I C E / P$ as shown in Fig. 20. It should be noted that for this comparison, a roughness height of $.5 \mathrm{~mm}$ and a 'd-shift' of $2 \%$ of the chord was used in LEWICEIP.

The main improvement of the current model is in the reduced effect of these immeasurable parameters on the solution. Figure 13 showed the variation of ice shape prediction by $L E W I C E / P$ using 'd-shifts' of $2 \%$ and $4 \%$ of chord, while Fig. 21 shows the effect of varying roughness for the values of $0.1 \mathrm{~mm}, 0.5 \mathrm{~mm}$, and $1.0 \mathrm{~mm}$ using $L E W I C E / P$. By contrast, the same exercise was performed using $L E W I C E / T N G$. These results are shown in Figs. 21 and 22 . As can be seen in these plots, much less variation in ice shape prediction is exhibited using LEWICE/TNG. The current variation due to 'd-shift' is due to the fact that the velocity is not changing linearly near the surface, hence using different ' $\mathrm{d}$-shifts' in the interpolation procedure causes a slight difference in the collection efficiency, especially near the impingement limits. Since LEWICE/ TNG overrides the roughness level input and uses the criteria described earlier, the input roughness has almost no effect on the solution. The difference shown is because if there is ice forming at a specific location at time step $n+1$ when no ice or water was present at time step $n$, then the model does not have a roughness value available. Until this loophole is closed, the input roughness is used in this region, hence the slight difference at the icing limits.

\section{Future Work}

The model used for predicting a roughness height is in the early stages of development and needs to be better defined. The main benefit of this model is that it allows the flow solution to exert greater control over the ice accretion prediction. This may not be a beneficial feature when using potential flow, as the solution for iced airfoils is very irregular. An attempt will be made to incorporate this new algorithm into the LEWICE/NS program. The geometry modification routines will also be examined. Recently, Hansmant has suggested alternative ice growth mechanisms which need to be explored.

After closely examining the close-up videos, one physical effect stands out which is not well predicted by this program. This is in the area of collection efficiency prediction. Experimental work in quantifying colleclion efficiency has always been performed on clean airfoils. Since potential flow programs are reasonably reliable for this situation, the collection efficiency should be well predicted. In glaze conditions where horns are produced and leading edge separation may occur. the collection efficiency may not be well predicted. No experimental data is yet available to confirm this, so an analysis will be performed using Naviér-Stokes and potential flow programs to identify the difference in prediction of collection efficiency. The ice shape prediction shown in Figure 19 has approximately $15 \%$ more ice than the experimental ice shape tracing. However, in the experiment, all of the water which impinges will freeze somewhere on the airfoil (except for a very small amount of evaporation). In the program, there is a large amount of runback water flow off the airfoil. If all of this runback water were to freeze, there would be approximately twice as much ice on the airfoil. This means that impingement levels for hom ice shapes is well overpredicted by a potential flow program.

\section{CONCLUSIONS}

Several additional physics of ice accretion were added to the existing model. Slight improvement has been made to the ice prediction capabilities as a result. The major improvement has been a marked decrease in the sensitivity of the program to the input values for 'sand-grain' roughness and for ' $\mathrm{d}$-shift'. Optimization of the droplet trajectory routines results in a $30 \%$ decrease in the overall computational time.

\section{REFERENCES}

1)Messinger, B. L., "Equilibrium Temperalure of an Unhealed Icing Surface as a Function of Airspeed." $J$. of the Aeronautical Sciences, vol. 20. no. I. Jan. 1953. pp. 29-42.

2)Ruff, G. A. and B. M. Berkowitz, "Users Manual for the NASA Lewis Ice Accretion Prediction Code (LEWICE)," NASA CR 185129, May 1990.

3)Olsen, W. and E. Walker, "Experimental Evidence for Modifying the Current Physical Model for Ice Accrelion on Aircraft Surfaces." NASA TM 87184, 1986. 
4) Iansman. R. J.. A. Reehorst, and J. Sins. "Analysis of Surface Roughness Generation in Aircraft lce Accretion." AIAA-92-0298. Jan. 1992.

5/Cebeci. T., Chen. H. H., and N. Alemdaroglu. "Forlified LEIIICE with Viscous Effects." AIAA 90-0754.

6)Rios. M.. "Icing Simulations Using Jones' Density Formula for Accreted Ice," AIAA-91-0556.

7)Poinsatte. P. E., "Heat Transfer Measurements From a NACA 0012 Airfoil in Flight and in the NASA Lewis Icing Research Tunnel." NASA CR 4278, March 1990.

8) Yamaguchi, K., "Improved Ice Accretion Prediction Techniques Based on Experimental Observations of Surface Roughness Effects on Heal Transfer, - MS Thesis, Massacliusetts Institute of 'Technology, Canıbridge Massachuselts, May 1990.

9)AI-Khalil, K. M., "Numerical Simulation of an Aircraft Anti-Icing System Incorporating a Rivulet Model for the Runback Water," PhD Dissertation, University of Toledo. Toledo, Ohio, Jan. 1991.

10)Wright, W. B., "Simulation of Two-Dimensional Icing. De-lcing and Anti-Icing Phenomena," PhD DisserIation, University of Toledo. Toledo, Ohio. Dec. 1991.

II)Macklin, W. C., "The Density and Structure of Ice Formed by Accretion," Quarterly Journol of the Roval Metemolengical Seciety, January 1962, Vol. 88, No. 3375, pp. $30-50$.

(2).Jones, K. F., "The Density of Natural Ice Accretions." Fourth International Conference on Atmospheric Icing of Structures, 1988, pp. 114-117.

1.3)Macklin, W. C., and G. S. Payne, "A Theoretical Sudy of the Ice Accretion Process," Quanerly Journal of the Roval Meteorological Society, 1967, Vol. 93, pp. 19521.3.

14)Schlichting, H., "Turbulent Boundary Layers in Compressible Flow," in Boundary-Layer Theory. F. J. Cerra. ED. New York. New York: McGraw-Hill, 1979, chapt. XXIII. pp. 713-715.

15)Shin, J. and T. H. Bond, "Experimental and Computational lce Shapes and Resulting Drag Increase for a NACA 0012 Airfoil, NASA TM 105743, Jan. 1992.

\section{FIGURES}

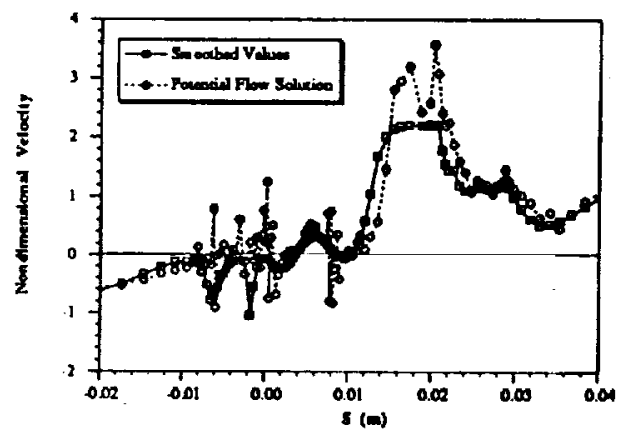

Figure 7. Effect of Smoothing the Flow Solution

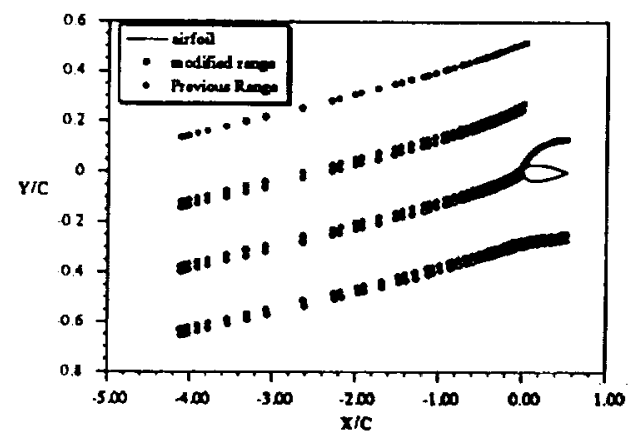

Figure 8. Optimization of Range Routine 


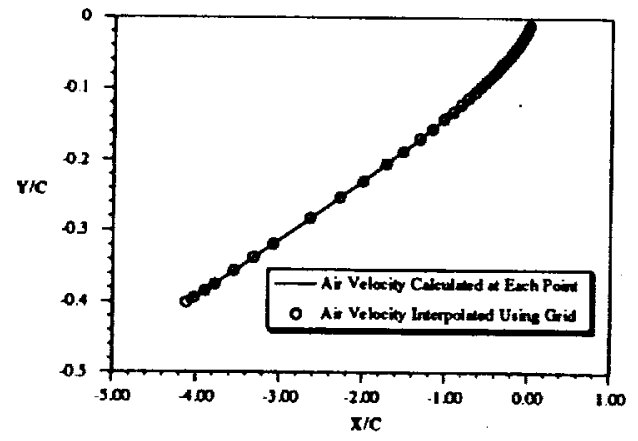

Figure 9. Drop Trajectory Using Interpolated Velocities

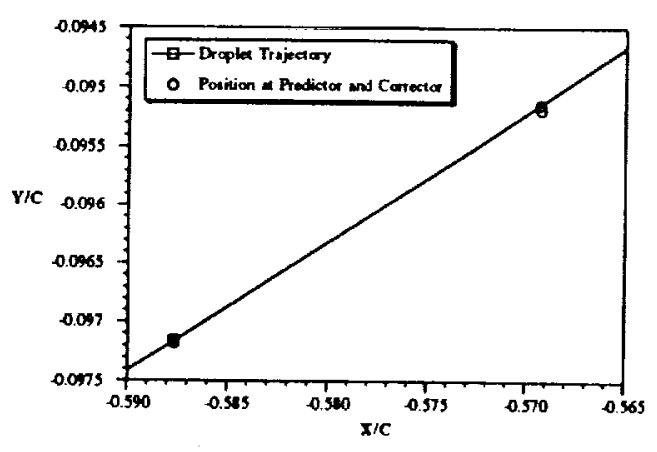

Figure 10. Drop Position at Two Different Time Sieps

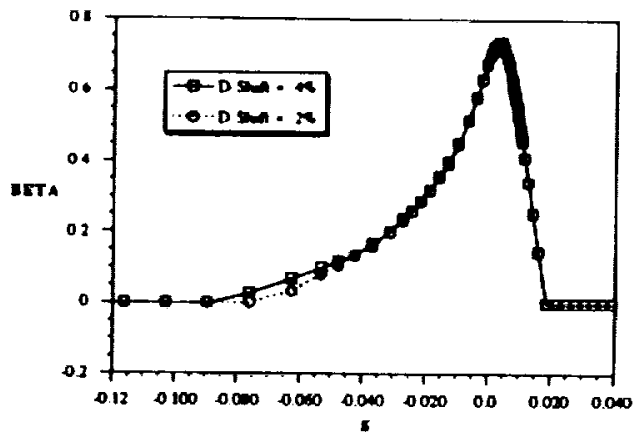

Figure 11. Variation of Beta with D-Shift: LEWICE/TNG

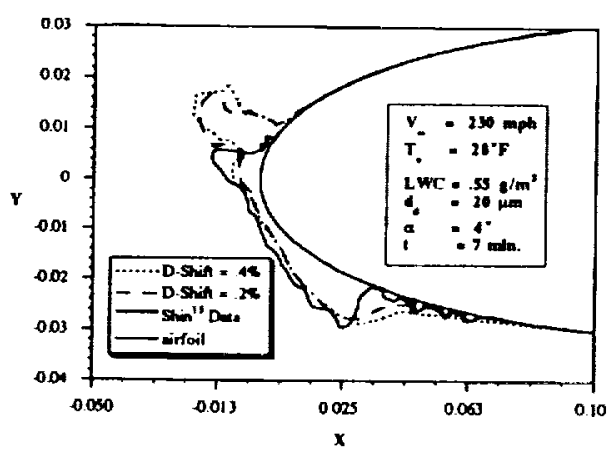

Figure 12. Variation of Ice Shape with D-Shift: LEWICE/ TNG 


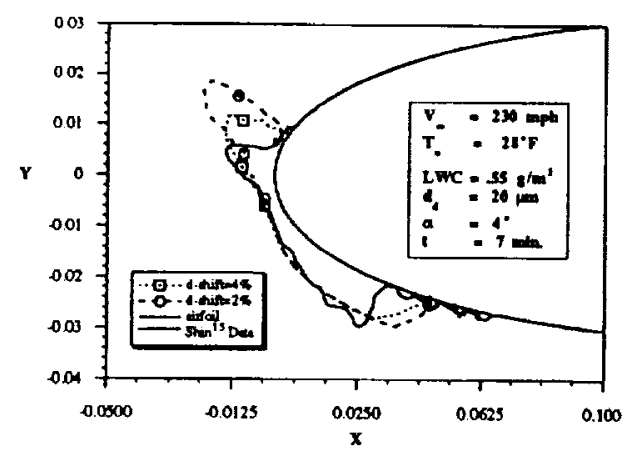

Figure 13. Variation of Ice Shape with d-Shift: LEWICE/P

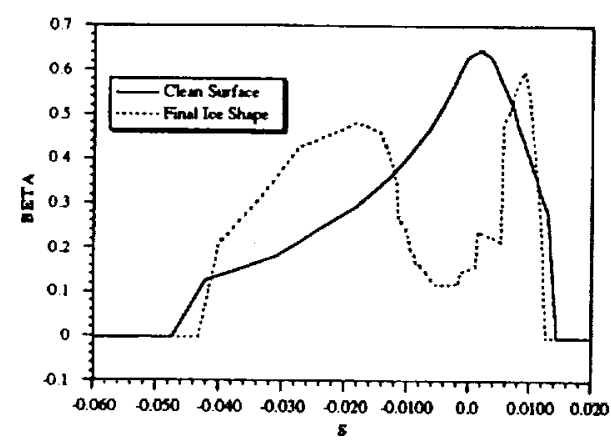

Figure 14. Change in Collection Efficiency with Time

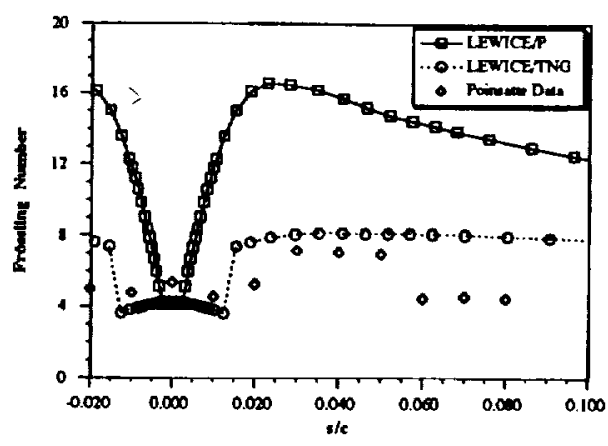

Figure 15. Comparison of Frössling Number with Poinsatte Data

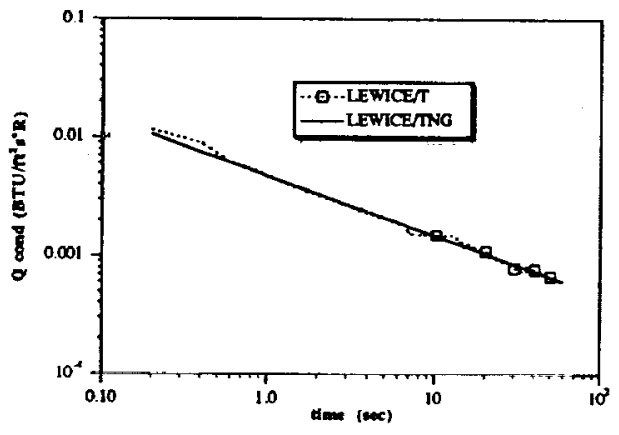

Figure 16. Comparison of LEWICE/TNG Conduction Approximation to LEWICE/T 

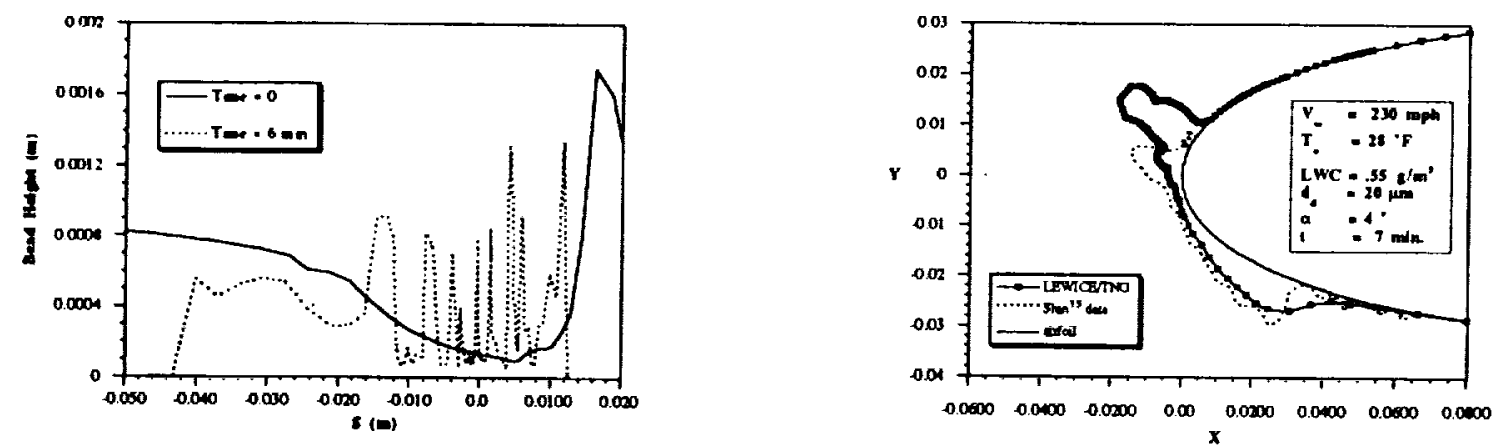

Figure 17. Change in Bead Height Prediction with Time

Figure 19. Comparison of LEWICE/TNG Ice Shape with Experimental Data
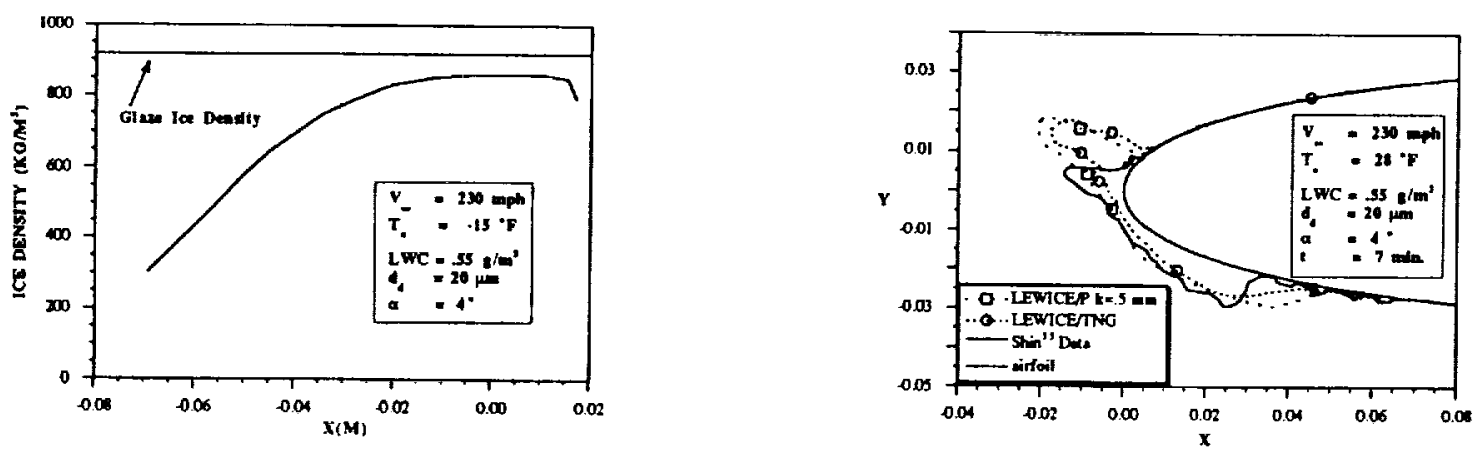

Figure 18. Sample Variation of Ice Density with Distance

Figure 20. Ice Shape Comparison for LEWICE/P and LEWICE/TNG 


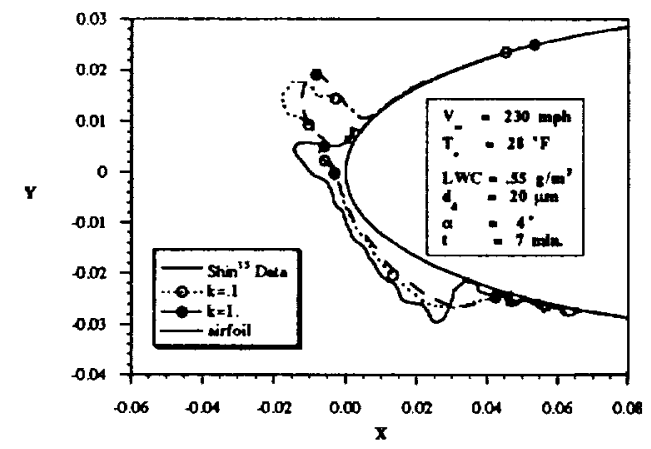

Figure 21. Variation of Ice Shape with Roughness: LEWICE/P

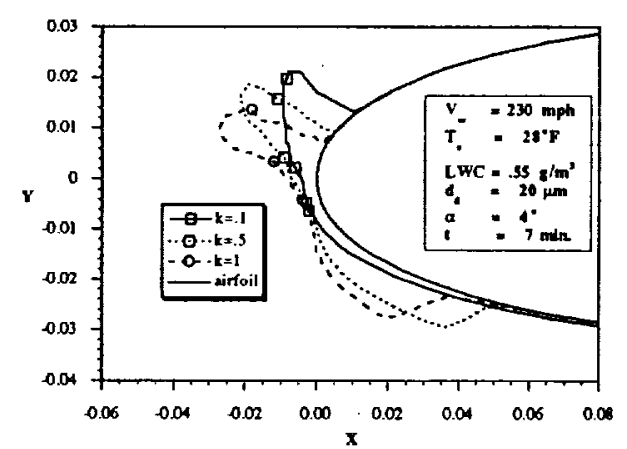

Figure 22. Variation of Ice Shape with Roughness: LEWICE/TNG 


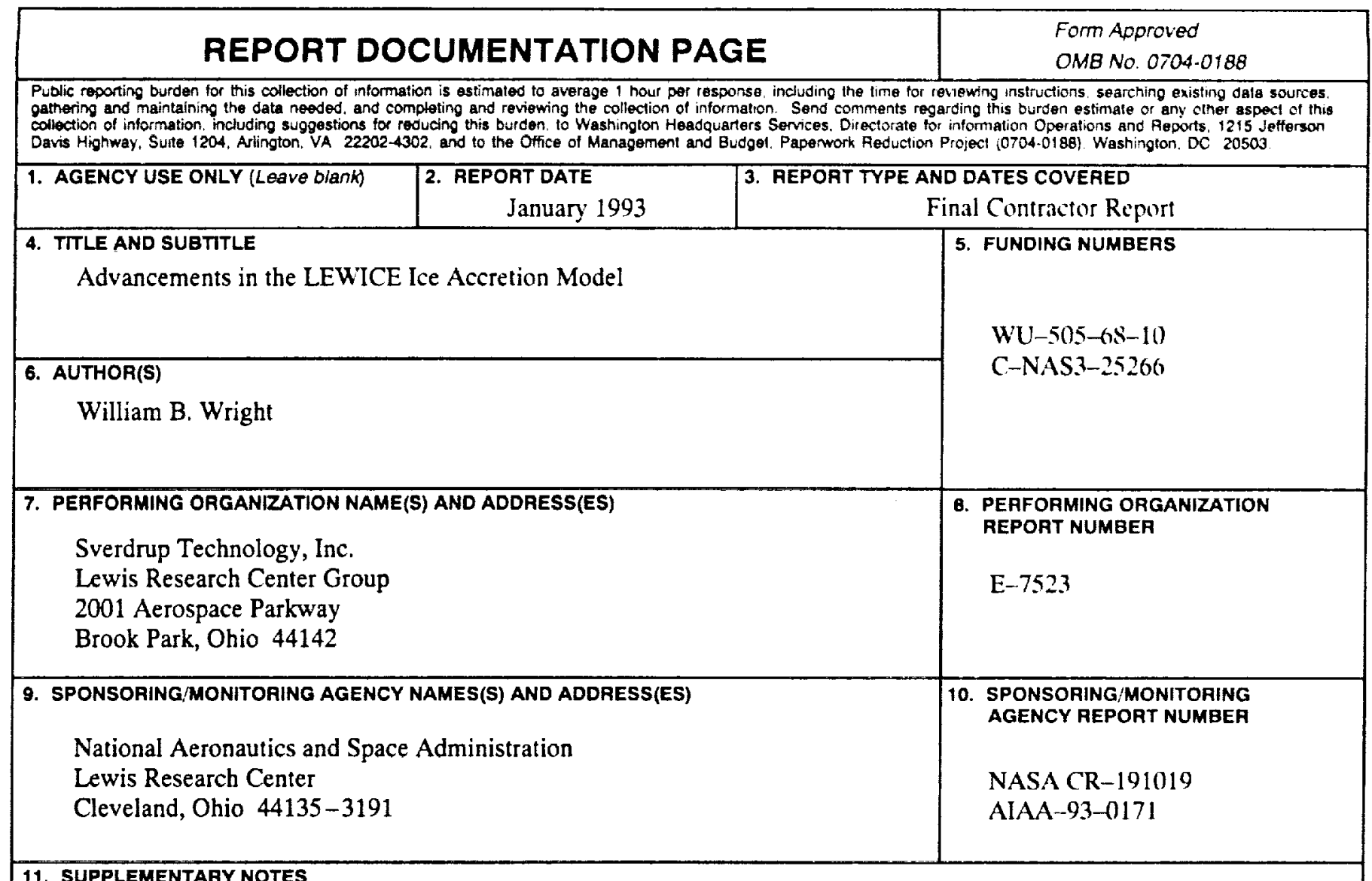

11. SUPPLEMENTARY NOTES

Prepared for the 31st Aerospace Sciences Meeting and Exhibit sponsored by the American Institute of Aeronautics and Astronautics, Reno, Nevada, January 11-14, 1993. Project Manager, John Reinmann, (216) 433-3900.

12a. DISTAIBUTION/AVAILABILITY STATEMENT

12b. DISTRIBUTION CODE

Unclassified - Unlimited

Subject Category 34

\section{ABSTRACT (Maximum 200 words)}

Recent evidence has shown that the NASA/Lewis Ice Accretion Model, LEWICE, does not predict accurate ice shapes for certain glaze ice conditions. This paper will present the methodology used to make a first attempt at improving the ice accretion prediction in these regimes. Importance is given to the correlations for heat transfer coefficient and ice density, as well as runback flow, selection of the transition point, flow field resolution, and droplet trajectory models. Further improvements and refinement of these modules will be performed once tests in NASA's Icing Research Tunnel, scheduled for 1993, are completed.

\begin{tabular}{|c|c|c|c|}
\hline \multicolumn{3}{|c|}{$\begin{array}{l}\text { 14. SUBJECT TERMS } \\
\text { Icing; Computational methods }\end{array}$} & $\begin{array}{c}\text { 15. NUMBER OF PAGES } \\
18 \\
\text { 16. PRICE CODE } \\
\text { AO3 } \\
\text { 20. LIMITATION OF ABSTRACT }\end{array}$ \\
\hline
\end{tabular}

